\title{
The correlation of electrical charge with strain on stressed rock samples
}

\author{
D. Triantis, C. Anastasiadis, and I. Stavrakas
}

Laboratory of electric properties of materials, Technological Educational Institution of Athens, Department of Electronics, 12210, Athens, Greece

Received: 3 July 2008 - Revised: 29 September 2008 - Accepted: 29 September 2008 - Published: 24 November 2008

\begin{abstract}
Laboratory experiments on rock samples have shown electric signal emissions when the samples are subjected to temporal stress increase especially when the samples approach failure. These electric signals are attributed to the generation and propagation of microcracks that guide the sample to mechanical failure.

In this work the temporal evolution of electric charge release is studied for marble samples subjected to stress at a constant rate up to fracture and it is correlated to the respective recordings of the yielded strain.

The results exhibit a systematic linear correlation between electric charge and deformation, with a constant proportionality factor independent of stress rate magnitude. This linear correlation, which is in accordance with the Moving Charged Dislocations (MCD) model, exists from the instant that the marble samples are driven to the non-linear region of mechanical behaviour due to the applied stress, and more precisely to the Crack Propagation Zone (CPZ) up to the prefailure phase.
\end{abstract}

\section{Introduction}

Laboratory investigations that show the existence of electric signal emissions during a full cycle of rock deformation have received considerable attention in recent years. These electric emissions have been attributed to several potential sources like the existence of quartz (Nitsan, 1977; Ogawa et al., 1985; Eccles et al., 2005), fluid movement causing the electrokinetic effect (Eccles et al., 2005; Ishido and Mizutani, 1981; Yoshida et al., 1998), point defects (Varotsos and Alexopoulos, 1986) and electron emissions (Brady and Rowell, 1986; Enomoto and Hashimoto, 1990).

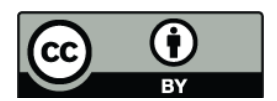

Correspondence to: D. Triantis (triantis@ee.teiath.gr)
When dealing with quartz-free rocks with extremely low internal moisture and low porosity, the piezoelectric and the electrokinetic effects are not considered as strong underlying physical mechanisms to support the existence of electric signal emissions. A model that is applicable for this case was proposed by Slifkin (1993) and was further developed by Vallianatos and Tzanis (1998), Tzanis and Vallianatos (2002) and explains electric signal emissions due to dislocation and other defect movements that cause local polarization. This model is known as Moving Charged Dislocations (MCD) model.

Papers of experimental laboratory recordings and analyses of electric signals emitted under temporally varying uniaxial compressional stress upon rock samples like marble and amphibolite have been conducted (Anastasiadis et al., 2004, 2007a, b; Stavrakas et al., 2004; Triantis et al., 2007). The electric current emitted during such temporal stress variation leading to a catastrophic process and to sample fracture has been rendered under the term "Pressure Stimulated Current" (PSC). The technique applied in order to show up and record the above described signals is rendered under the term "PSC technique". A statistical analysis of PSC time series obtained from calcite samples has recently been done by Vallianatos and Triantis (2008).

The Pressure Stimulated Currents are characterized by very low peak values ( $1 \mathrm{pA}$ up to $100 \mathrm{pA}$ ) and they emerge from the background noise level when the applied stress on the sample leads to the non-linear deformation range (out of the limits of Hooke's law) and specifically when the sample is led to the Crack Propagation Zone (CPZ). Intense PSC emissions are observed slightly before fracture of the sample.

According to the MCD model the observed transient electric variation is related to the non-stationary accumulation of deformation. The expected emission of Pressure Stimulated Current (PSC), is proportional to the strain rate (Vallianatos

Published by Copernicus Publications on behalf of the European Geosciences Union. 


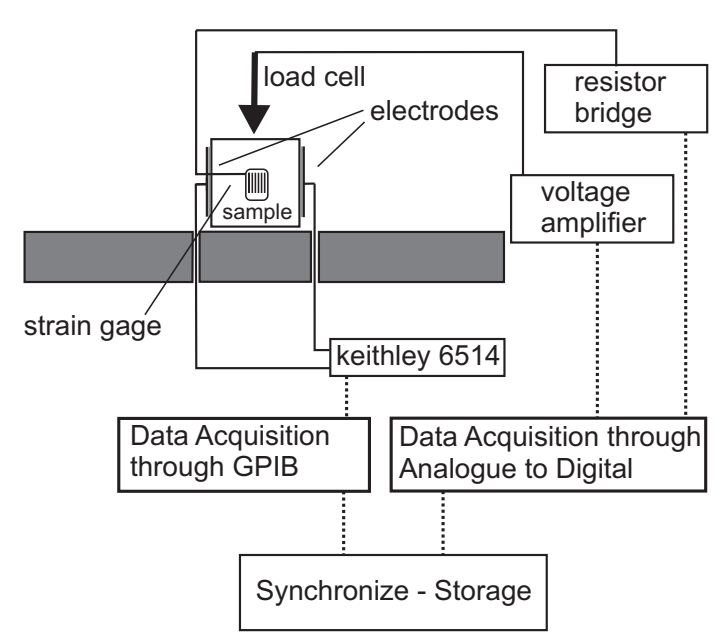

Fig. 1. A schematic representation of the experimental arrangement to conduct the measurements including both mechanical and electrical measurement systems.

et al., 2004), i.e.:

$\operatorname{PSC}(t) \propto \frac{d \varepsilon(t)}{d t}$

where $\varepsilon(t)$ is the temporal variation of strain during the axial compressional variation of stress $\sigma(t)$. According to Eq. (1) the electrical charge $Q(t)$, that is released in a time window $t=0$ to $t$ is given by:

$Q(t)=\int_{0}^{t} \operatorname{PSC}(t) d t=\Gamma \cdot \varepsilon(t)$

where $\Gamma$ is a scaling factor, that according to the MCD model formalism contains physical parameters of the material (Vallianatos et al., 2004). $t=0$ is defined as the instant at which the pressure stimulated current is at a very low level just before emerging from noise level.

This work intends to verify experimentally the proportionality described by Eq. (2) after a series of measurements based on the PSC technique, with simultaneous recordings of PSC, stress and strain.

\section{Samples and experimental technique}

The PSC technique was applied to a series of marble samples that were extracted from the same rock mass collected from Mount Penteli (Dionysos). The samples were properly formulated to similar prisms measuring $35 \mathrm{~mm} \times 35 \mathrm{~mm} \times 60 \mathrm{~mm}$ and prepared for the experiments. The stress was applied through an axis parallel to the long edge. The physical and chemical properties of this kind of marble have already been presented in bibliography (Kourkoulis et al., 1999; Kleftakis et al., 2000; Stavrakas et al., 2003). The specific characteristic of the samples is that they

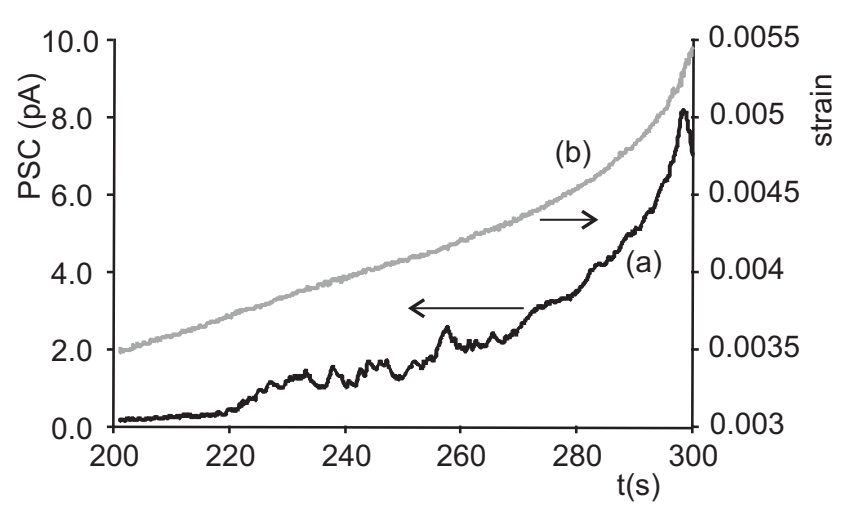

Fig. 2. The temporal development of the emitted PSC (curve a) and of deformation (curve b), while applying constantly increasing stress.

have very small quartz content $(0.2 \%)$, while their principal content is calcite $(98 \%)$. Systematic measurements of the strength of these samples have indicated that their fracture limit is in the range between $46 \mathrm{MPa}$ and $55 \mathrm{MPa}$.

A description of the experimental arrangement for PSC measurements as well as of all measurement procedures has been thoroughly presented in the previous works (Stavrakas et al., 2003; Anastasiadis et al., 2004, 2007a). Figure 1 shows this experimental arrangement, equipped with a strain measuring device. The strain was measured using Kyowa strain gauges attached on the Microlink-770, $120 \Omega$ resistor bridge.

\section{Experimental results - discussion}

The experimental results of the application of the PSC technique on five marble samples will be presented here. In these experiments, the uniaxially applied compressional stress $\sigma$ increases linearly and the emitted PSC is recorded. The temporal development of stress can be described by:

$\sigma=a \cdot t$

where a is the stress rate. At $t=t_{f}=\sigma_{\max } / a$, the sample fails, where $\sigma_{\max }$ is the ultimate compressional stress strength. The only differing parameter in the experimental procedures of the five PSC recordings is stress rate.

Figure 2, presents the temporal development of the emitted PSC (curve a) in the marble sample coded M01, given that the applied compressional uniaxial stress was constantly increasing at a rate of $0.17 \mathrm{MPa} / \mathrm{s}$ up to fracture. In the same diagram, curve $b$ describes the temporal evolution of the deformation of the sample. A weak electric signal below $2 \mathrm{pA}$ appears in the time between $220 \mathrm{~s}$ and $250 \mathrm{~s}$. During this time, it can be observed in Fig. 2 (curve b), the deformation rate is practically constant and the material is within the linear range with respect to its mechanical behaviour because the sample is being loaded at a linearly increasing uniaxial 


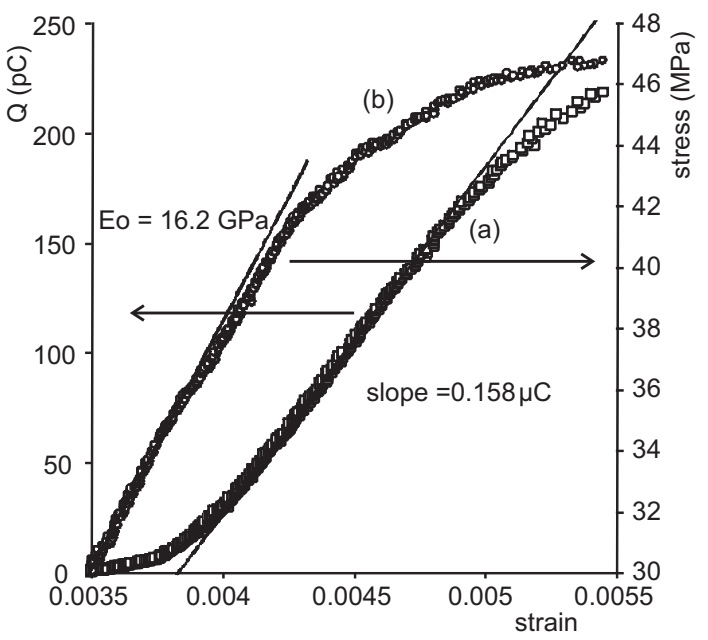

Fig. 3. Correlation of the released charge with respect to strain (curve a) and the stress-strain curve display (curve b).

compressional stress. In this case the following relationship holds between the applied stress $\sigma(t)$ and the strain $\varepsilon(t)$ :

$\sigma(t)=\mathrm{E}_{0} \cdot \varepsilon(t)$

where $E_{0}$ is the Young's modulus of the undamaged material, which after calculation was found to be equal to $16.2 \mathrm{GPa}$. This weak electric signal comes from early crack generations of low concentration within the bulk material. A considerable signal amplitude increase can be observed after $250 \mathrm{~s}$ when deformation gets values greater than 0.004 , and its increasing rate is already evident. In this case, the applied stress is greater than the "yield stress" $\left(\sigma_{y}\right)$ the Young's modulus gradually decreases and the material enters damage range. Also in this case a variable that quantifies the damage grade is introduced as "damage variable", $\alpha$, (Turcotte and Shcherbakov, 2006) and is described by the following formula:

$\sigma=\sigma_{y}+E_{0} \cdot(1-\alpha) \cdot\left(\varepsilon-\varepsilon_{y}\right)$

where $\varepsilon_{y}=\sigma_{y} / E_{0}$. The damage variable varies between 0 and 1.

The above become more evident if we observe the depicted parameters in Fig. 3. Curve a corresponds to the electrical charge $Q(t)$, calculated from the $\operatorname{PSC}(t)$ recordings with the use of Eq. (2), and correlated with the corresponding strain values $\varepsilon(t)$. The stress-strain curve of the same sample is measured on a secondary axis (curve b). The linear behaviour of the electrical charge with respect to strain appears for values $\varepsilon>0.004$. Based on the stress-strain curve this value corresponds to a characteristic value of the strain $\varepsilon_{y}\left(\varepsilon_{y}=0.004\right)$, with a corresponding $\sigma_{y}=39 \mathrm{MPa}$ approximately. Since the stress $\sigma(t)$ exceeds the value $\sigma_{y}$ we can define the crack formation and propagation region (Lavrov, 2005). Due to the fact that PSC emissions are mainly attributed to crack formation and propagation it is expected

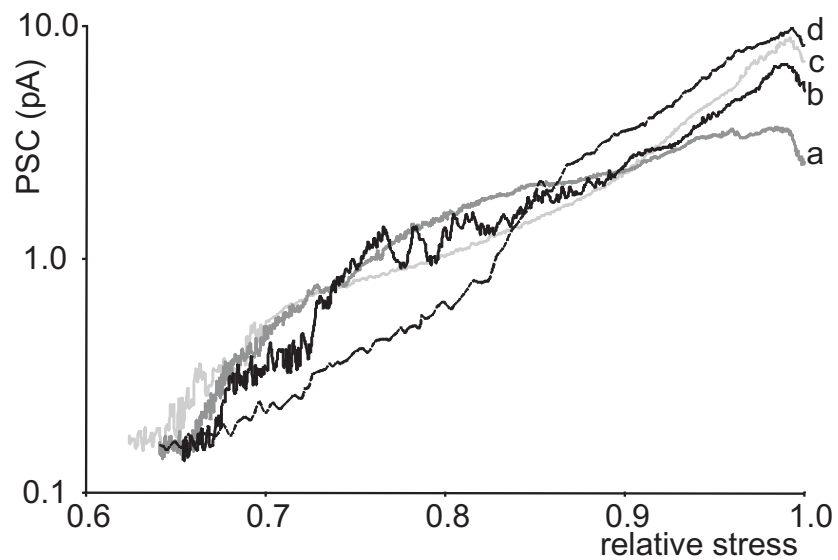

Fig. 4. PSC recordings $a, b, c$ and d, for four marble samples each of them suffering uniaxial compressional stress at different constant rates up to fracture, $0.135 \mathrm{kPa} / \mathrm{s}, 0.159 \mathrm{kPa} / \mathrm{s}, 0.188 \mathrm{kPa} / \mathrm{s}$ and $0.196 \mathrm{kPa} / \mathrm{s}$ respectively, with respect to relative stress.

that when these mechanisms are activated, they dominate the sample bulk thus, PSC excitation is intense. Consequently, the electric charge starts increasing more intensely having a linear relationship with the continuously increasing strain. Thus, the theoretical prediction of Eq. (2) coming from the MCD model is experimentally verified.

The proportionality constant $\Gamma$ has the value $0.158 \mu \mathrm{C}$, which is characteristic for the material as will be obvious later. The linear relationship between electric charge and strain seems to be prevalent till the material approaches adequately the failure point. In this experiment the deviation from the linear law is observed when the applied stress reaches the value $46 \mathrm{MPa}$ approximately. Having in mind that the sample failed at $47 \mathrm{MPa}$, this deviation from the linear law corresponds to a value of relative compressional stress $\left(\hat{\sigma}_{\mathrm{NL}}\right)$ equal to 0.98 approximately. It is speculated that the formation of the fracture plane that takes place at these high stresses and the extensive cracking that is guided through the slip plane, limit the available conductive path in the sample bulk and a consequent obstacle on the emitted PSC is created. This is the reason, as can be seen in Fig. 2, for the PSC to have a peak in the vicinity of fracture. This peak creates a $(d Q / d \varepsilon)<\Gamma$. Next, the experimental results related to the remaining four similar marble samples (M02, M03 M04 M05), will be presented. The only differentiation comes from the different rate of the applied uniaxial compressional stress. The corresponding four PSC recordings are depicted in Fig. 4. In order for a comparison of the PSC recordings to be made, they are rendered with respect to the relative stress. It is a characteristic feature of all four electric emissions (PSC), is that they show similar behaviour qualitatively. As it is expected, the emitted electric signals begin to be obvious when the relative compressional stress reaches the limit of 0.7 , which has repeatedly been verified in previous experiments (Stavrakas et al., 2004; Anastasiadis et al., 

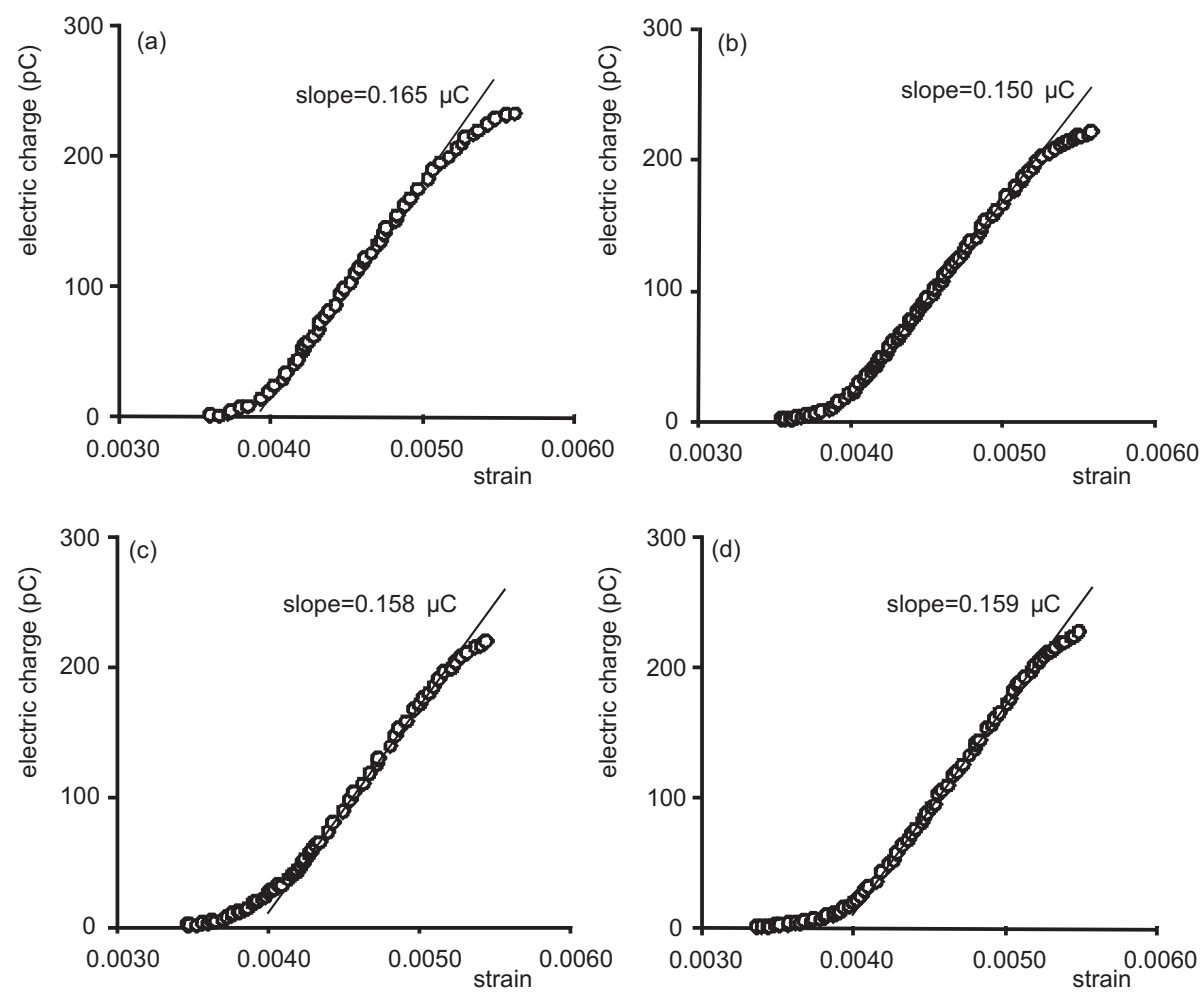

Fig. 5. Correlation of the electric charge $\mathrm{Q}(\mathrm{t})$ with the respective values of strain $\varepsilon(t)$ for the PSC recordings (a), (b), (c) and (d), depicted in Fig. 4.

Table 1. The experimental characteristics of the four representative samples and the experimental results for each sample.

\begin{tabular}{|c|c|c|c|c|c|c|}
\hline $\begin{array}{l}\text { sample } \\
\text { code }\end{array}$ & $\begin{array}{l}\text { PSC } \\
\text { recording }\end{array}$ & $\begin{array}{l}\text { stress rate } \\
(\mathrm{kPa} / \mathrm{s})\end{array}$ & $\begin{array}{l}\text { failure } \\
(\mathrm{MPa})\end{array}$ & $\begin{array}{l}\text { total electric charge } \\
\qquad Q_{t}(\mathrm{nC})\end{array}$ & $\Gamma(\mu \mathrm{C})$ & $\hat{\sigma}_{\mathrm{NL}}$ \\
\hline M01 & $\begin{array}{l}\text { Fig. } 2 \\
\text { Curve a }\end{array}$ & 0.170 & 47.1 & 0.219 & 0.158 & 0.981 \\
\hline M02 & $\begin{array}{l}\text { Fig. } 4 \\
\text { Curve a }\end{array}$ & 0.135 & 50.3 & 0.233 & 0.165 & 0.964 \\
\hline M03 & $\begin{array}{l}\text { Fig. } 4 \\
\text { Curve b }\end{array}$ & 0.159 & 49.1 & 0.220 & 0.150 & 0.977 \\
\hline M04 & $\begin{array}{l}\text { Fig. } 4 \\
\text { Curve c }\end{array}$ & 0.188 & 52.9 & 0.219 & 0.158 & 0.988 \\
\hline M05 & $\begin{array}{l}\text { Fig. } 4 \\
\text { Curve d }\end{array}$ & 0.196 & 49.8 & 0.226 & 0.159 & 0.99 \\
\hline
\end{tabular}

2007a). All four PSC recordings seem to have a peak just before failure. Although each peak is different, the calculations of the total released electric charge $Q_{t}$ (see Table 1), lead to the same value approximately. This fact verifies a previous theoretical and experimental notice (Triantis et al., 2007), that the total charge released during stress application up to fracture reaches almost the same values irrespectively of the stress rate.

Figure 5 shows the results of correlation of the electric charge $Q(t)$ with the corresponding values of strain $\varepsilon(t)$.
All four experiments confirm a linear law between $Q(t)$ and $\varepsilon(t)$, when the applied stress is greater than the yield stress. This finding is in accordance with the underlying mechanism that is described by the MCD model and justifies the existence and the quantitative characteristics of the PSC emissions. Specifically, and according to Eq. (2) a linear relation between the total released charge and the mechanical deformation strongly exists when the stress becomes greater than the yield stress up to the vicinity of fracture. Deviation from this linearity is observed at high deformation values where 


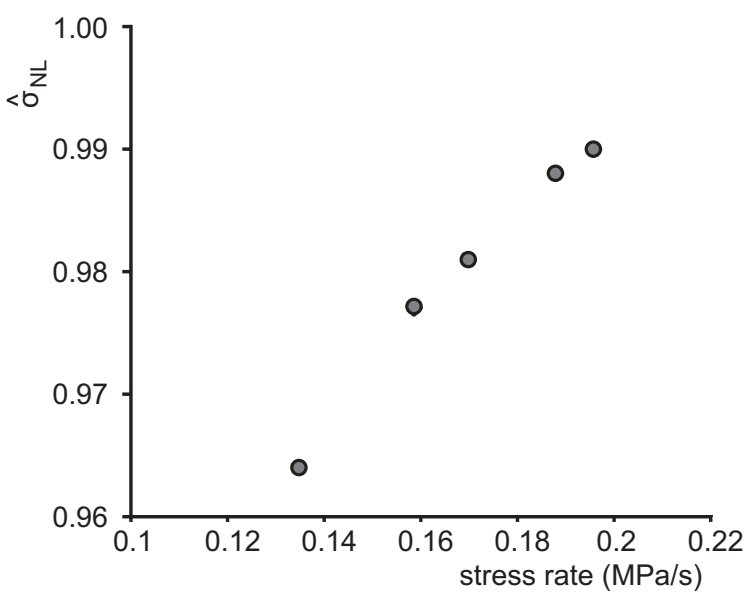

Fig. 6. The correlation between the $\hat{\sigma}_{\mathrm{NL}}$ and the applied stress rate.

practically the sample shows meso-scopic fracture. As far as the scaling factor $\Gamma$ is concerned, values approximating $0.16 \mu \mathrm{C}$ were found, which are practically independent of the stress rate (see Table 1). Thus, the factor $\Gamma$ can be considered as a characteristic of the material.

The relative compressional stress $\left(\hat{\sigma}_{\mathrm{NL}}\right)$, in which the deviations from the linear law take place, seems to be slightly differentiated (see Table 1). The experimental results indicate that when the rate of the applied uniaxial compressional stress increases, the deviation from the linear law takes place at greater values of relative stress (see Fig. 6). This correlation between the $\hat{\sigma}_{\mathrm{NL}}$ and the stress rate must be related to the fact that the lower the stress rate is, the longer the creep effect holds and the consequent fracture plane formation lasts longer.

\section{Concluding remarks}

In this work a correlation is attempted between the electric signal emitted from marble samples during a stressing process (PSC technique) and the deformation of the samples. A linear relationship between the electric charge that is released during the described process and deformation begins to be observed when the applied stress exceeds the value of yield stress. This linear correlation remains till the sample approaches failure. The fact that in a series of experiments on the same material, with different stress rates, the scaling factor $\Gamma$ is practically constant verifies the linear correlation between the Pressure Stimulated Current and the strain rate. The experimental verification of the above linear relationship seems to support the theoretical predictions of the moving charged dislocation (MCD) model that supports the existence of a proportionality between the electric current density and the strain rate providing a good interpretation of the underlying mechanisms of electric signal emission. Finally, a significant finding extracted from this series of experiments is that when the material reaches failure a clear deviation from the linearity between the released charge and the strain is observed. Thus, such a non-linear behaviour can be used to predict the upcoming event of fracture.

Edited by: P. F. Biagi

Reviewed by: two anonymous referees

\section{References}

Anastasiadis, C., Triantis, D., Stavrakas, I., and Vallianatos, F.: Pressure stimulated currents (PSC) in marble samples after the application of various stress modes before fracture, Ann. Geophys., 47, 21-28, 2004, http://www.ann-geophys.net/47/21/2004/.

Anastasiadis, C., Triantis, D., and Hogarth, C. A.: Comments on the phenomena underlying pressure stimulated currents (PSC) in dielectric rock materials, J. Mater. Sci., 42, 2538-2542, 2007a.

Anastasiadis, C., Stavrakas, I., Triantis D., and Vallianatos F.: Correlation of Pressure Stimulated Currents in rocks with the damage parameter, Ann. Geophys., 50, 1-6, 2007b, http://www.ann-geophys.net/50/1/2007/.

Brady, B. T. and Rowell, G. A.: Laboratory investigation of the electrodynamics of rock fracture, Nature, 321, 448-492, 1986.

Eccles, D., Sammonds, P. R., and Clint, O. C.: Laboratory studies of electrical potential during rock failure, Int. J. Rock Mech. Min., 42, 933-949, 2005.

Enomoto, J. and Hashimoto, H.: Emission of charged particles from indentation fracture of rocks, Nature, 346, 641-643, 1990.

Ishido, T. and Mizutani, H.: Experimental and theoretical basis of electrokinetic phenomena in rock-water systems and its applications to geophysics, J. Geophys. Res., 86, 1763-1775, 1981.

Kleftakis, S., Agioutantis, Z., and Stiakakis, C.: Numerical Simulation of the uniaxial compression test including the specimenplaten interaction, Computational methods for shell and spatial structures, IASS-IACM, 2000.

Kourkoulis, S. K., Exadaktylos, G. E., and Vardoulakis, I.: Unotched Dionysos-Pentelicon marble beams in three point bending: The effect of nonlinearity, anisotropy and microstructure, Int. J. Fracture, 98, 369-392,1999.

Lavrov, A.: Fracture-induced Physical Phenomena and memory Effects in Rocks: A Review, Strain, 41, 135-149, 2005.

Nitsan, U.: Electromagnetic emission accompanying fracture of quartz-hearing rocks, Geophys. Res. Lett., 4, 333-337, 1977.

Ogawa, T., Oike, K., and Mirura, T.: Electromagnetic radiations from rocks, J. Geophys. Res., 90, 6245-6249, 1985.

Slifkin, L.: Seismic electric signals from displacement of charged dislocations, Tectonophysics, 224, 149-152, 1993.

Stavrakas, I., Anastasiadis, C., Triantis, D., and Vallianatos, F.: Piezo stimulated currents in marble samples: precursory and concurrent-with-failure signals, Nat. Hazards Earth Syst. Sci., 3, 243-247, 2003, http://www.nat-hazards-earth-syst-sci.net/3/243/2003/.

Stavrakas, I., Triantis, D., Agioutantis, Z., Maurigiannakis, S., Saltas, V., Vallianatos, F., and Clarke, M.: Pressure stimulated currents in rocks and their correlation with mechanical proper- 
ties, Nat. Hazards Earth Syst. Sci., 4, 563-567, 2004, http://www.nat-hazards-earth-syst-sci.net/4/563/2004/.

Triantis, D., Stavrakas, I., Anastasiadis, C., Kyriazopoulos, A., and Vallianatos, F.: An analysis of Pressure Stimulated Currents (PSC), in marble samples under mechanical stress, Phys. Chem. Earth, 31, 234-239, 2006.

Triantis, D., Anastasiadis, C., Vallianatos, F., Kyriazis, P., and Nover, G.: Electric signal emissions during repeated abrupt uniaxial compressional stress steps in amphibolite from KTB drilling, Nat. Hazards Earth Syst. Sci., 7, 149-154, 2007, http://www.nat-hazards-earth-syst-sci.net/7/149/2007/.

Turcotte, D. L. and Shcherbakov, R.: Can damage mechanics explain temporal scaling laws, in: brittle fracture and seismicity?, Pure Appl. Phys., 163, 1031-1045, 2006.

Tzanis, A. and Vallianatos, F.: A physical model of electrical earthquake precursors due to crack propagation and the motion of charged edge dislocations, in: Seismo Electromagnetics: Lithosphere-Atmosphere-Ionosphere Coupling, edited by: Hayakawa, M. and Molchanov, O. A., TERRAPUB, Tokyo, 117130, 2002.
Vallianatos, F. and Tzanis, A.: Electric current generation associated with the deformation rate of a solid: Preseismic and coseismic signals, Phys. Chem. Earth, 23, 933-938, 1998.

Vallianatos, F., Triantis, D., Tzanis, A., Anastasiadis, C., and Stavrakas, I.: Electric Earthquake Precursors: From Laboratory Results to Field Observations, Phys. Chem. Earth, 29, 339-351, 2004.

Vallianatos, F. and Triantis, D.: Scaling in Pressure Stimulated Currents related with rock fracture, Physica A: Statistical Mechanics and its Applications, 387(19-20), 4940-4946, 2008.

Varotsos, P. and Alexopoulos, K.: Thermodynamics of point defects and their relation with bulk properties, North-Holland, Amsterdam, 403-406, 1986.

Yoshida, S., Clint, O. C., and Sammonds, P. R.: Electric potential changes prior to shear fracture in dry and saturated rocks, Geophys. Res. Lett., 25, 1577-1580, 1998. 